\title{
Changing World of Health Care Finance- Private and Social Health Insurance
}

\author{
Shwetha H.L ${ }^{1, *}$, Padma K. Bhat ${ }^{2}$ \\ ${ }^{1}$ Vydehi Institute of Dental Sciences and Research Centre, India \\ ${ }^{2}$ Department of Public Health Dentistry, Rajarajeswari Dental College and Hospital, Bangalore-560060, Karnataka, India \\ *Corresponding Author: searchdrshwetha@gmail.com
}

Copyright (C) 2014 Horizon Research Publishing All rights reserved.

\begin{abstract}
The way in which healthcare is financed is critical for equity in access to healthcare. A common feature of all health systems is the distinction between public and private health care. This distinction refers to both the finance and the provision of health services. Before launching any major health initiative, there ought to be a well articulated vision of health care system for the country, and public health policy must be devised to realise that vision. Ideally, certain basic health services, including inpatient care, must be made available to every member of the society[19]. These services must be paid through insurance, which means that every member must have health insurance cover or at least have access to health insurance, with government subsidising insurance premium, in full or in part, for those who cannot afford it. Health insurance gives the insured population an entitlement to health services. It is therefore important to ensure that the health infrastructure exists to provide those services and that there is some incentive to comply with the insurance. Skill-building for the personnel involved, and capacity-building of all the stakeholders involved, would be a critical component for ensuring the success of any health insurance programme.
\end{abstract}

Keywords Private Insurance, Social Insurance, Health Care, Finance

\section{Introduction}

Health care financing is defined as the "function of a health system concerned with the mobilization, accumulation and allocation of money to cover the health needs of the people, individually and collectively, in the health system".

The purpose of health financing is to make funding available, as well as to set the right financial incentives to providers, to ensure that all individuals have access to effective public health and personal health care[1].

Financing is the most critical of all determinants of a health system. The nature of financing defines the structure, the behavior of different stakeholders and quality of outcomes[2]. It is closely and indivisibly linked to the provisioning of services and helps define the outer boundaries of the system's capability to achieve its stated goals[3].

\section{Evolution of Health Care Finance}

Early in the history of health care, government or charities financed services for groups of the population for whom they perceived a duty of care[4]. For example, hospitals for the poor existed in India, China, Arabia and medieval Europe .

For the more affluent, private (or voluntary) health insurance was pioneered in Europe as early as the eighteenth century. In the nineteenth century, private insurance was developed throughout Europe and spread to North and South America.

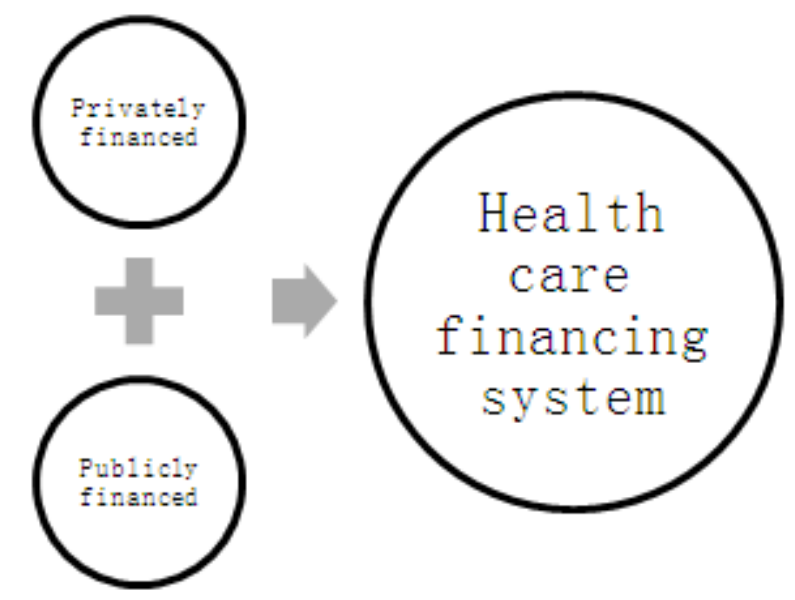

Figure 1. Health care financing system is broadly classified under private and public finance

Meanwhile, social (or compulsory) insurance was introduced in Germany for industrial workers in 1883, building on the existing voluntary precedents[5]. Coverage was extended later to family members, other employees and pensioners. Payroll-based social insurance systems developed steadily in Europe, and later in Latin America and 
Asia[6]. Health care financing system is broadly classified under private and public financed(Figure 1).Privately financed envisages out of pocket payments and private health insurance(Figure 2). Social insurance and taxation based system falls under the category of publicly financed(Figure 3).
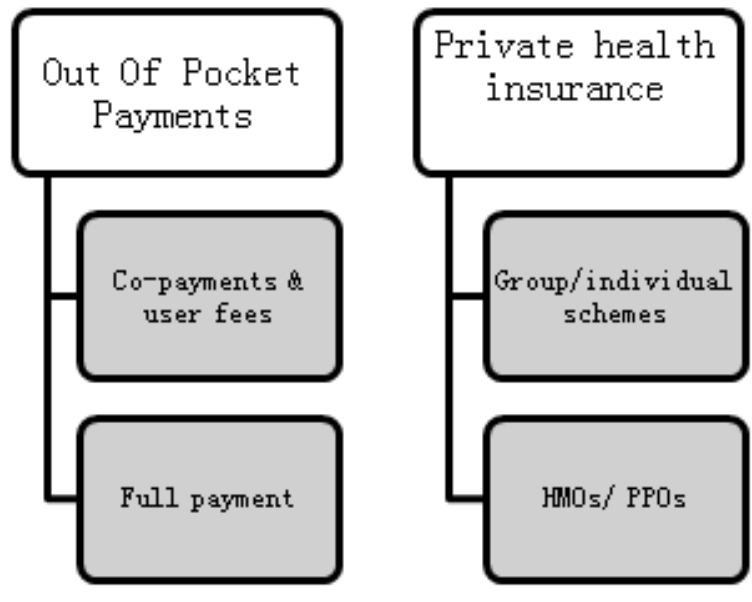

Figure 2. Privately financed
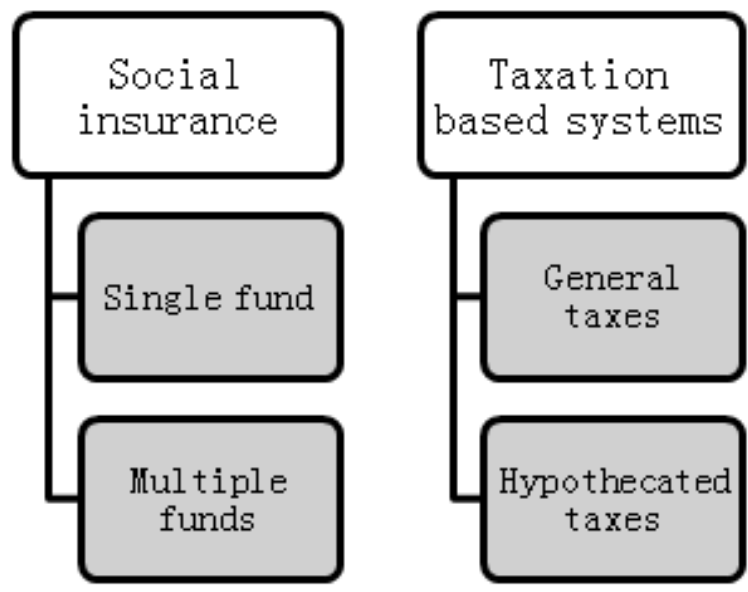

Figure 3. Publicly Financed

\section{The Changing World of Health Services Finance}

The means of paying for health care is an issue of concern in most countries. Governments are worried about the economic and political consequences of the increasing cost of providing health services and try to limit spending through tighter controls. There is a large body of literature to suggest that many countries are dissatisfied with the existing methods of finance and delivery of health services[7]. During the last decade, governments have introduced a series of reforms. Though the motives and types of reform may differ, there have been some common themes:

- Separation of purchaser and provider responsibilities. This concept refers to the separation of responsibility for purchasing and providing health care between two different organizations. In general, funders (government and insurance companies) have two options: to run their own hospitals or to act as purchasers and buy services from providers, including the private sector. The underlying idea is that purchasers contract with those providers offering best value for money and that this increases efficiency of service delivery.

- Redefinition of the role of the state in responsibility for health care.

- Encouragement of the private sector.

- Encouragement of competition between providers

- Alternative sources of funding: economic crises have exacerbated the problems of financing the health sector and governments have sought alternative ways of mobilizing resources.

When considering the last of these it is helpful to distinguish between macro-level and micro-level changes[8]. Macro-level changes involve a change in the basic principle of funding, such as the move from social insurance towards a system mainly based on taxation.

Sociopolitical context of different health care system over the world that made health care financing in different mechanisms rather than only health insurance. These are probably important enough to consider some kind of mixture of major health care financing systems. One is the UK national health service, and they are going to improvise it by introducing more entrepreneurial management expertise into the system. Another one is national health insurance of Canada, Taiwan, Korea. Advantages are incentives and the means to negotiate economical and high quality care. The consumer has freedom of choice of providers and has considerable potential for achieving micro-economic efficiency. This system provides universal coverage and a desirable level of equity. United states has subsumed managed care like Health Maintenance Organisation and Medical Savings Account. The advantage of managed care are cost-containment and micro-efficiency and there is an incentive for providers to minimize service.

\subsection{The Public-Private Distinction}

A common feature of all health systems is the distinction between public and private health care. This distinction refers to both the finance and the provision of health services. The concept of ownership is used to distinguish whether an organization belongs to the private or public sector[9]. The notion of a public agency refers not only to government organizations but also to public bodies with statutory responsibilities like social insurance companies. The private sector can be divided into for profit and not for profit organizations. The former include the drugs industry and private hospitals or clinics in which some (sometimes most) of any financial surplus goes out of the organization to the shareholders. Not for profit organizations reinvest any financial surplus in their organization by developing 
facilities and training staff[10]. The distinction from for profit isn't so clear-cut as some surplus in not for profit organizations can also go out of the organization in the form of enhanced salaries and bonuses.

\section{Private Health Insurance}

It is conventional to define private insurance as those which fall outside the direct control of government. Private insurance financing may be individual (although this is rare except in highly regulated contexts) or operate through employers or other purchasing organizations [11]. Equity considerations in private insurance market can generate inefficiency and market failure as it involves tradeoff between desired distribution and the distorted incentives that accompany such redistribution[12]. The private insurance sector has developed (or rediscovered) several methods of enhancing the quality and cost-effectiveness of care, which are subsumed under the term managed care. Health Maintenance Organization and Preferred Provider Organization are couple of predominant managed care organizations.

The choice between public health financing or private insurance is hardly available to countries like India because of their governments' limited ability to marshal sufficient resources to finance health spending, and also because the nature of employment (where majority of workers are self-employed, or do not have a formal employer or steady employment) is such as to provide little scope for payroll taxes[13]. Given this, heavy reliance on private spending is necessary for financial reasons, notwithstanding the declared policy of the state to provide universal, comprehensive primary health services to the entire population. Private spending may also be desirable on efficiency grounds[14]. But the form that bulk of private spending takes need to change from out-of-pocket payments to private insurance. Conceptually, a society can be thought of as consisting of two groups of individuals, those who can afford to buy health insurance that promises certain "minimum" level of benefit, and those who cannot afford to buy the "minimum" benefit on their own and need some public subsidy[15]. As mentioned above, development of private health insurance may take care of those who can afford to buy insurance. For those who cannot afford, alternate approaches with some public subsidy are suggested.

Developments on the health insurance front will not leave the poor unaffected. Even though private for-profit insurance companies are not expected to voluntarily provide health insurance cover to the poor, the poor may still be affected on account of the influence that development of health insurance will have on the supply of such services[16]. Furthermore, the poor may also directly benefit if insurance regulations are specifically designed to achieve redistribution and equity objectives. At the minimum the government must ensure that (i) the liberalization of insurance market provides value for money for the direct beneficiaries (ii) the poor are not adversely affected by the liberalization. However, the government can definitely aim higher by ensuring that the poor too benefit from the developments in health insurance[17].

The likely impact of developing voluntary insurance on the poor is far from clear. There are both potential benefits and risks associated with it. Development of health insurance would influence supply of health services both in terms of its quality and price[18]. It would also influence the extent of public funds available for subsidising the poor. The potential benefits and risks are formally listed below:

\subsection{Potential Benefits}

- If the introduction of evidence-based medicine trickles down to other providers that are used more often by the poor, the poor could benefit from the improvement in quality in the private sector;

- If public subsidy to the non-poor who join health insurance decreases, greater public resources may be available for providing subsidy to the poor

\subsection{Potential Risks}

- The gap between the poor access at present and the required access may increase with cost escalation;

- As the non-poor make a switchover from public to private hospitals there is a risk of political support for public financing getting reduced which would impact the poor by excluding them quality care from private market or by deteriorating quality and weakening support for public services.

The pro-poor recommendations are: (i) reduce the public subsidy to the wealthy by charging full cost recovery to the insured who use private insurance (ii) define minimum package of services cover that include preventive, maternity, and catastrophic cases (iii) encourage informal community financing schemes, for example, managed care schemes through NGOs with less regulation and lower capital deposit requirements.

Before launching any major health initiative, there ought to be a well articulated vision of health care system for the country, and public health policy must be devised to realise that vision. Ideally, certain basic health services, including inpatient care, must be made available to every member of the society[19]. These services must be paid through insurance, which means that every member must have health insurance cover or at least have access to health insurance, with government subsidising insurance premium, in full or in part, for those who cannot afford it. For the upper-and middle-income people, private health insurance market with effective and sound regulation can take care of health financing. However, with the development of private insurance market, only half the country's population can at best be reached. The other half, which consists of lowincome population ( $30 \%$ of the population below the poverty line and add to it another $20 \%$ living dangerously close to 
this line) is likely to remain outside the ambit of private health insurance unless there is an explicit social obligation in this respect which can come only from insurance regulator[20]. Even though the government's approach is to support voluntary insurance rather than to expand the existing social insurance schemes, the following approaches may be suitable for the different sections of the society[21]. For the upper and the middle income people social insurance and voluntary insurance are suggested to be the two dominant forms of financing health care. Even for lowincome people who are employed in the formal sector, social insurance may be a better way of providing health protection. For the low-income people, neither who are working in unorganized sector, neither government provided nor market mediated arrangement is appropriate that alternate approaches are needed. One among that alternate arrangement is community based health insurance schemes which offer valuable lessons for policy makers.

In India, there appears to be three basic designs, depending on who is the insurer. In Type I (or HMO design), the hospital plays the dual role of providing health care and running the insurance programme. In Type II (or Insurer design), the voluntary organisation is the insurer, while purchasing care from independent providers. And finally in Type III (or Intermediate design), the voluntary organisation plays the role of an agent, purchasing care from providers and insurance from insurance companies.

\section{Future Directions of Private Health Insurance}

De-Tariffing: De-tariffing has taken on the air of a magic bullet $\|$ in the insurance industry and there is no question that health insurance prices should reflect real costs. Other possible effects of de-tariffing that may be less positive are reduction of benefits and number of people covered by the price-sensitive individual market, and shifting of some groups to self insurance as prices increase with resulting loss of tax deductibility. Nonetheless, it is still likely that detariffing will be a positive move for the insurance industry.

Changes in the Third Party Administrators Market: Have begun to develop strategic options that go beyond simply administering health insurance policies for others. To accomplish this some are beginning to partner with international reinsurance companies (including selling stakes in their own organizations) to offer their combined services to existing insurance companies which lack appropriate expertise in health care.

\section{Social Insurance}

Social health insurance is insurance operated by a public agency. Social insurance contributions are usually either regressive (a flat per capita mandate) or proportional (a flat payroll tax rate). Social insurance aims at four means of cross- subsidization:

1. from the healthy to the ill: contributions regardless of individual risk;

2. from the young to the old: smaller contributions from the elderly;

3. from the rich to the poor: contributions are a fixed percentage of earnings;

4. from singles to families: equal contributions regardless of the number of dependants[22].

The extent of additional cross-subsidization may vary between social insurance schemes and there is also variation in a number of other aspects, such as:

- Coverage: social insurance may either cover part of the population or the whole population. High earners may be allowed to insure privately if their earnings are above a defined income.

- Subsidies: governments may subsidize social insurance funds to keep contributions affordable for the poor.

- Number of funds: social insurance systems may consist of several funds or a single fund for the whole population.

- Contributions: usually compulsory, payroll deducted, progressive with income, but voluntary contributions and flat rates are also possible.

- Ownership of health care facilities by social insurance agencies is uncommon though agencies in Latin America act as providers as well as purchasers of health care.

- Benefit package: may vary between basic and comprehensive health care and include benefits in cash and kind[23].

\section{The Desirability and Feasibility of Social Insurance}

\subsection{Payroll Deductions}

Social health insurance is normally provided through a system of payroll contributions to a health fund[24]. It is typical (although not essential) for the total contribution to be calculated as a percentage of income.

\subsection{Labour Market Structure}

Social insurance for health is funded by a percentage deduction from incomes (or salaries), and this depends on there being an agreed measure of income.

\subsection{Social Health Insurance and National Infrastructure}

Social health insurance requires some additional administrative arrangements for collecting contributions and providing access to care, and it can only be effectively developed if these arrangements can be put in place[25]. The 
overall level of education within the country can be important in this respect.

\subsection{Social Health Insurance and Health Care Infrastructure}

Health insurance gives the insured population an entitlement to health services. It is therefore important to ensure that the health infrastructure exists to provide those services and that there is some incentive to comply with the insurance[26].

\section{Conclusion}

Generalization of the health care financing system needs to be addressed through Solidarity, delegation, free choice in turn will galvanize universal coverage, accessibility and accountability. Health care financing system in general should possess desirable characteristics such as equity, universality, efficiency, quality, facilitation of innovation, freedom of choice, user friendliness, longterm sustainability and finally syndication of free market mechanism.

In light of the fiscal crisis facing the government at both central and state levels, in the form of shrinking public health budgets, escalating health care costs coupled with demand for health-care services, and lack of easy access of people from the low-income group to quality health care, health insurance is emerging as an alternative mechanism for financing of health care. Health policy-makers and health systems research institutions, in collaboration with economic policy study institutes, need to gather information about the prevailing disease burden at various geographical regions; to develop standard treatment guidelines, to undertake costing of health services for evolving benefit packages to determine the premium to be levied and subsidies to be given; and to map health care facilities available and the institutional mechanisms which need to be in place, for implementing health insurance schemes[27]. Skill-building for the personnel involved, and capacity-building of all the stakeholders involved, would be a critical component for ensuring the success of any health insurance programme. The success of any social insurance scheme would depend on its design, the implementation and monitoring mechanisms which would be set in place and it would also call for restructuring and reforming the health system, and developing the necessary prerequisites to ensure its success. The article argues for "strengthening public investment and expenditure in the health sector and suggests possible options for doing this. It also calls for a reform of the existing healthcare system by restructuring it to create a universal access mechanism which also factors in the private health sector. The article concludes that it is important to over-emphasize the fact that health is a public or social good and so cannot be left to the vagaries of the market."

\section{REFERENCES}

[1] Optimal Taxation and Social Insurance with Endogenous Private Insurance. American Economic Journal: Economic Policy 2 (May 2010): 85-114

[2] Estes C

L,BodenheimerT:Payingforlong-termcare.WestJMed1994; 160:64-69

[3] Ball R M:Public-private solution to protection against the cost of long-term care. J Am Geriatr Soc 1990; 38:156-163

[4] MeinersM,McKayH:Private versus social long-term care insurance:Beware the comparison. Generations 1990; $14: 32-36$

[5] Nadel MV: Long-term care insurance partnerships (Letter). Washington, DC, General Accounting Office, publication No. HRD-92-44R, 1992, pp 1-7

[6] The Origins of Private Social Insurance: Public Policy and Fringe Benefits in America, 1920-1950. A J S Volume 97 Number 5 (March 1992): 1416-50

[7] Sherry A. Glied . Health Care Financing, Efficiency, And Equity . http://www.nber.org/papers/w13881

[8] Bennett, S./Creese, A./Monasch, R. 1998: Health Insurance schemes for People Outside Formal Sector Employment. WHO: Division of Analysis, Research and Assessment.

[9] Tanzi V, Schuknecht L. Public spending in the 20th century: Global perspective. Cambridge: Cambridge University Press; 2000 .

[10] World Bank. World Development Report 2004: Making services work for poor people. World Bank; 2003:256-7.

[11] Ronald T. Ackermann. Support for National Health Insurance among U.S. Physicians: A National Survey : Ann Intern Med. 2003;139:795-801.

[12] Smith MB (1997) Trends in health care coverage and financing and their implications for policy. New England Journal of Medicine 337:1000-3.

[13] Griffin CC (1992) Health care in Asia: a comparative study of cost and financing. Washington, DC: World Bank.

[14] Hamel MB et al. (1996) Seriously ill hospitalized adults: do we spend less on older patients? Journal of American Geriatrics Society 44:1043-8.

[15] Hurst J (1992) The reform of health care: a comparative analysis of seven OECD countries. Paris: OECD.

[16] Normand C (1991) Economics, health and the economics of health. British Medical Journal 303:1572-7.

[17] Relman AS (1988) Assessment and accountability: the third revolution in medical care. New England Journal of Medicine 319:1220-2.

[18] Woolhandler S and Himmelstein DU (1997) Costs of care and administration at for-profit and other hospitals in the United States. New England Journal of Medicine 336:769-74.

[19] Grossman M (1972) On the concept of health capital and the demand for health. JournalofPoliticalEconomy80:223-55. 20. Grossman M (2004) The demand for health, 30 years later: a very personal retrospective and prospective reflection. 
Journal of Health Economics 23:629-36

[20] Godfrey C and Maynard A (1988) Economic aspects of tobacco use and taxation policy. British Medical Journal 297:339-43.

[21] Bryan S, Weatherburn G, Buxton M, Watkins J, Keen J and Muris N (1999) Evaluation of a hospital picture archiving and communication system. Journal of Health Services Research \& Policy 4:204-9.

[22] Eklund P and Stavem K (1995) Community health insurance through prepayment schemes in Guinea-Bissau, in Shaw RP and Ainsworth M (eds) Financing health services through user fees and insurance. Washington, DC: World Bank.
[23] Kutzin J and Barnum H (1992) Health insurance affects the delivery of health care in developing countries. Working paper. Washington, DC: World Bank.

[24] Normand C and Weber A (1994) The desirability of social health insurance, in Social Health Insurance: A Guidebook for Planning. Geneva: WHO.

[25] Schulenburg JMG (1994) The German health care system at the crossroads. Health Economics 3:301-3.

[26] Shaw RP and Griffin CC (1995) Health care in Sub-Saharan Africa through user fees and insurance. Washington, DC: World Bank. 